EXTENDED REPORT

\title{
A randomised controlled trial of intra-articular corticosteroid injection of the carpometacarpal joint of the thumb in osteoarthritis
}

\author{
G K Meenagh, J Patton, C Kynes, G D Wright
}

Ann Rheum Dis 2004;63:1260-1263. doi: 10.1136/ard.2003.015438

See end of article for authors' affiliations

.....................

Correspondence to: Dr G K Meenagh,

Department of

Rheumatology, Musgrave

Park Hospital, Stockman's

Lane, Belfast BT9 7JB, UK;

garymeenagh@

yahoo.co.uk

Accepted

19 November 2003

\begin{abstract}
Objective: To investigate the efficacy of corticosteroid injections into the carpometacarpal joint of the thumb (CMCJ) in patients with osteoarthritis.

Design: A double blind, randomised controlled trial using 40 hospital referred patients with CMCJ osteoarthritis who received intra-articular injections of $5 \mathrm{mg}$ triamcinolone hexacetonide $(0.25 \mathrm{ml})$ or sterile $0.9 \%$ saline $(0.25 \mathrm{ml})$. Injections were given under imaging control.

Main outcome measures: The primary outcome was improvement in a pain visual analogue score (VAS) of $20 \%$ at 24 weeks. In addition patients were assessed at 4,12 , and 24 weeks for joint stiffness, joint tenderness, and physician and patient global assessments. Hand radiographs were evaluated for the degree of CMC joint space narrowing and marginal osteophytes according to the OARSI atlas.

Results: Baseline clinical variables were not significantly different between the two treatment groups. There was no improvement in the VAS of pain at 24 weeks. At each assessment point there was no significant difference between the steroid and placebo groups in median values for joint stiffness, joint tenderness, or patient and physician global assessments. Non-parametric analysis of each group individually revealed statistically significant improvements in patient and physician global assessments at weeks 4, 12, and 24 in the placebo group and at weeks 4 and 12 in the steroid group.

Conclusions: No clinical benefit was gained from intra-articular steroid injection to the CMCJ in moderate to severe osteoarthritis compared with placebo injection.
\end{abstract}

$\mathrm{T}$ he carpometacarpal joint (CMCJ) of the thumb is commonly targeted by the osteoarthritic process. The condition occurs both as a localised form of osteoarthritis and as part of generalised nodal osteoarthritis. Estimates of the prevalence of the disorder show a female preponderance with a ratio of 1:3 between men and women. ${ }^{1}$ A recent study showed that $25 \%$ of patients with hand osteoarthritis had isolated evidence of CMCJ osteoarthritis, while it was present as part of nodal osteoarthritis in 53\% of cases. ${ }^{2}$ Several factors have been associated with the development of degenerative changes in the CMCJ, including increased thumb base joint laxity $^{3}$ and greater grip strength. ${ }^{4}$

The general principles for management of CMCJ osteoarthritis follow those for peripheral joint osteoarthritis in general. No specific guidelines on the treatment of this form of osteoarthritis exist, but the recommended options include the use of a combination of simple analgesia, muscle strengthening physiotherapy, and a thumb spica splint together with intra-articular injections of corticosteroid. ${ }^{5}$

The exact place of intra-articular steroid injections in CMCJ osteoarthritis is not well documented and there is only anecdotal evidence to support its use. ${ }^{6}$ While the intraarticular administration of high molecular weight corticosteroids to peripheral joints with osteoarthritis is well documented, ${ }^{7-10}$ the present study is the first to examine the efficacy of steroid joint injection in patients with symptomatic osteoarthritis of the CMCJ in a randomised, double blind, placebo controlled trial.

\section{METHODS}

Ethical approval for the study was obtained from the local research ethics committee.

\section{Patient ascertainment}

Hospital-referred patients with symptomatic CMCJ osteoarthritis were recruited from the department of rheumatology, Royal Victoria Hospital, Belfast. All patients satisfied the American College of Rheumatology (ACR) criteria for the classification of hand osteoarthritis. ${ }^{11}$ We excluded patients with a history of inflammatory arthritis, previous thumb base trauma, or previous steroid joint injection to either CMCJ.

Patients satisfying the entry criteria gave written informed consent before randomisation to a double blind, placebo controlled trial carried out between February 1999 and November 2002. Randomisation was done using a table of random numbers which was balanced after every four patients. The list of random numbers corresponded to numbered opaque syringes available at the time of joint injection.

\section{Procedures}

Patient assessment

Full patient assessment was carried out at baseline by an investigator blinded to the treatment given (JP). This consisted of the following:

- Self recorded thumb CMCJ pain, recorded using a $100 \mathrm{~mm}$ horizontal visual analogue score (VAS): $0=$ no pain; $100=$ worst pain ever.

- Patient global assessment.

- Physician global assessment.

Abbreviations: ACR, American College of Rheumatology; CMCJ, carpometacarpal joint; EULAR, European League Against Rheumatism; OARSI, Osteoarthritis Research Society International; VAS, visual analogue score 
- Assessment of joint tenderness by single fingertip pressure over the joint line located dorsal and volar to the abductor pollicis longus and extensor pollicis brevis tendons; this was graded $0=$ no tenderness; $1=$ pain; $2=$ pain+patient winces; 3 = pain+patient withdraws. ${ }^{12}$

- Duration of early morning joint stiffness, recorded in minutes.

The primary outcome was improvement in a pain VAS of $20 \%$ at 24 weeks.

\section{Injection method}

Injections were carried out under radiographic screening by a second investigator (GM), thereby blinding both patient and investigator. In cases of bilateral CMCJ osteoarthritis the more symptomatic joint was injected. Patients were positioned with the hand to be injected held in the semi-prone position, the joint line identified by palpation, and the needle tip inserted lateral to the abductor pollicis longus tendon. Needle tip position was confirmed using a Uroscop image intensifier to ensure accurate delivery of the injected substance. Opaque syringes were drawn up by a third investigator (CK) containing either $0.25 \mathrm{ml}(5 \mathrm{mg})$ of triamcinolone hexacetonide or $0.25 \mathrm{ml}$ of sterile $0.9 \%$ saline, and were used to inject the CMCJ under standard aseptic technique. The injected CMCJ was immobilised in a thumb spica splint for 48 hours.

Follow up and outcome assessment

Clinical assessment, as described above, was repeated at 4 , 12 , and 24 weeks by the same investigator who undertook the baseline preinjection assessment.

\section{CMC joint imaging}

Radiographic evaluation of the CMC joint was carried out before the joint injection. A standard postero-anterior view was taken of both hands, and CMC joint space narrowing and marginal osteophyte grading were assessed according to the OARSI atlas. ${ }^{13}$

\section{Statistical analysis}

We postulated that the smallest detectable difference between placebo and steroid injection which was likely to be clinically significant was $20 \%$. A non-parametric power calculation was used to estimate the numbers of patients required to show a $20 \%$ difference in VAS pain score between placebo and steroid groups at 24 weeks. For a two sided test with an $\alpha$ level of $5 \%$ and power of $80 \%$, we aimed to recruit 45 patients in each group. An intention to treat analysis was used. Patients not completing the full 24 week follow up period had their last measured indices carried forward. Data were analysed using the statistical analysis packages Microsoft ${ }^{\circledR}$ Excel 2000, SPSS/PC version 11 (SPSS Inc, Chicago, Illinois, USA).

The two intervention groups were compared for all numerical variables using the Mann-Whitney U test at each time interval. Within each treatment group the Wilcoxon signed ranks test was used to compare the difference in the median distribution of variables with time. In both statistical methods, significance was accepted at a probability $(p)$ value of $<0.05$.

\section{RESULTS}

Forty six patients with CMCJ osteoarthritis were invited to participate in the study and 40 (36 women and four men) agreed to take part. Mean duration of CMCJ symptoms was 8.2 years and 7.4 years in the placebo and steroid groups, respectively. Bilateral thumb CMCJ osteoarthritis was present in six patients who received placebo and in four who received steroid injection.

\section{Withdrawals}

Six patients who were eligible for the study chose not to participate. In the placebo group two patients failed to attend for the final 24 week assessment, and three in the steroid group also failed to attend the follow up (one at 12 weeks and two at 24 weeks). The throughput of patients is summarised in fig 1.

\section{Complications}

Recruitment proved difficult for this study, and only about $50 \%$ of the numbers required to satisfy the power calculation were identified over a three year period. This resulted in the early termination of the study. There were no adverse effects reported by patients in the follow up period after the joint injection.

\section{Baseline clinical assessments}

Baseline clinical characteristics of the participants were similar (table 1).

CMC joint space narrowing was also similar between the two groups, with $75 \%(\mathrm{n}=15)$ and $81 \%(\mathrm{n}=16)$ having grade 3 joint space narrowing in the placebo and steroid groups, respectively.

\section{Response to treatment}

Table 2 and fig 2 show the changes in median measurements compared with baseline within the two groups over time. The placebo group showed no significant improvement in VAS, joint stiffness, joint tenderness. There was, however, a significant improvement in both the physician's global assessment and the patient's global assessment, which was evident at all time periods. The steroid group also showed no significant improvement in VAS, joint stiffness, or joint

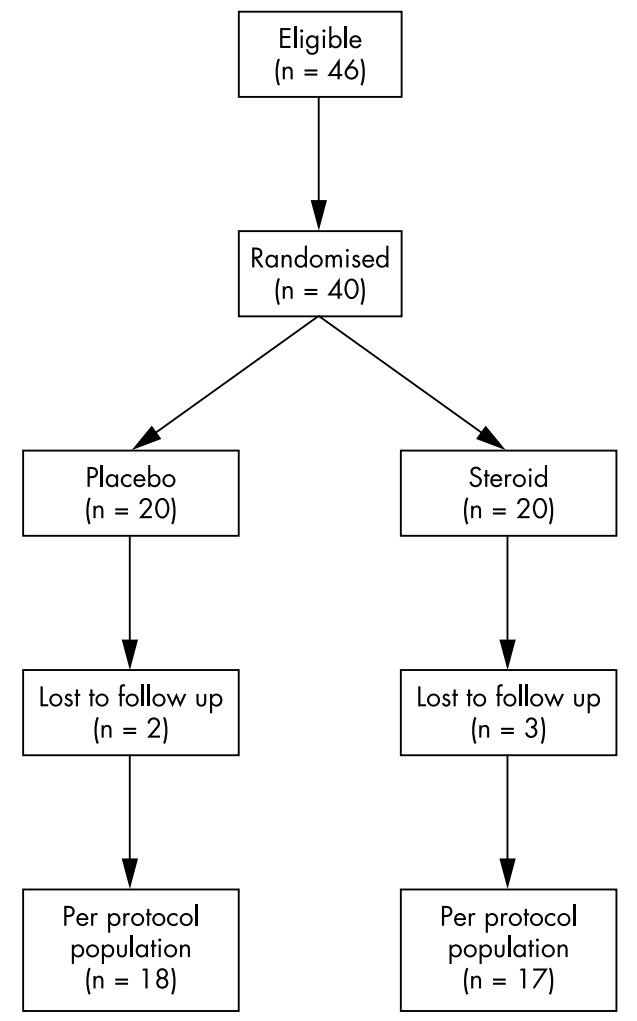

Figure 1 Trial profile. 
Table 1 Demographic features of 40 patients with carpometacarpal joint osteoarthritis, randomly assigned to receive placebo or steroid injection to the symptomatic thumb base joint

\begin{tabular}{lll}
\hline Clinical feature & Placebo & Steroid \\
\hline $\begin{array}{l}\text { Age (years), mean (range) } \\
\begin{array}{l}\text { Mean duration of symptoms } \\
\text { (years) }\end{array}\end{array}$ & $59.3(46$ to 69$)$ & 60.6 (41 to 71$)$ \\
$\begin{array}{l}\text { Female/male } \\
\text { Family history of hand }\end{array}$ & $17 / 3$ & 7.4 \\
$\begin{array}{l}\text { osteoarthritis } \\
\text { Dominant hand injected }\end{array}$ & 14 & $19 / 1$ \\
$\begin{array}{l}\text { Bilateral symptoms } \\
\text { Nodal osteoarthritis present }\end{array}$ & 14 & 14 \\
$\begin{array}{l}\text { VAS } \\
\text { Joint tenderness }\end{array}$ & $56(50$ to 78$)$ & $52(40$ to 72$)$ \\
$\begin{array}{l}\text { Physician's global assessment } \\
\text { Patient's global assessment }\end{array}$ & $2(1$ to 2$)$ & $2(1$ to 3$)$ \\
Joint stiffness & $4(3$ to 4$)$ & $3(2$ to 4$)$ \\
CMC joint space narrowing & $15(10$ to 30$)$ & 20 to 4$)$ \\
CMC osteophyte grade & $3(2$ to 4$)$ & $3(2$ to 4$)$ \\
\hline
\end{tabular}

Data are numbers or median ( $95 \%$ confidence interval) unless stated otherwise. The Wilcoxon signed rank was used to assess differences between the groups.

CMC, carpometacarpal; VAS, visual analogue score.

tenderness with time, but a significant improvement in both physician's global assessment and patient's global assessment was observed at 4 and 12 weeks, which returned to the baseline at 24 weeks.

\section{DISCUSSION}

This study shows the clinical outcome following intraarticular administration of corticosteroid to the CMCJ of the thumb in patients with primary osteoarthritis. Randomisation was successful, as indicated by the parity of baseline clinical characteristics of the participants. We found no significant improvement in VAS with either intervention over time, although beneficial effects on the patients' general wellbeing were observed in both groups. Radiographically our cohort had a high prevalence of moderately severe CMC joint space narrowing at baseline in both treatment arms of the study.

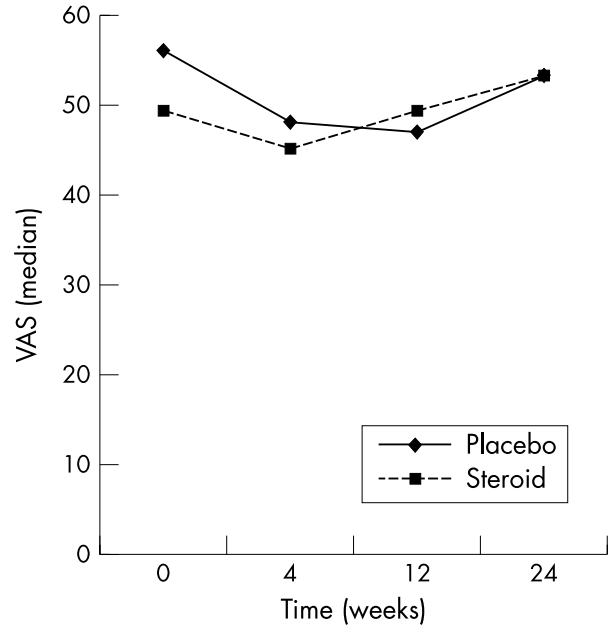

Figure 2 Graph showing the median visual analogue score $(\mathrm{mm})$ at each assessment point in the placebo and steroid groups. No significant decrease in VAS is seen in either group.

This is the first randomised controlled trial investigating the effect of corticosteroid injection of the CMCJ in osteoarthritis. Dieppe ${ }^{14}$ suggested that corticosteroid injection of the CMCJ in osteoarthritis was of clinical use, but stressed that this view was based purely on anecdotal evidence provided by Meyer ${ }^{6}$ and highlighted the absence of control data. At present there are no recognised guidelines for the management of CMCJ osteoarthritis. Recent guidelines on the management of peripheral joint osteoarthritis were published by the ACR ${ }^{15}$ and by EULAR. ${ }^{16}$ Both concentrate on the medical management of lower limb osteoarthritis and do not specifically mention the CMCJ. While both encourage the use of non-pharmacological interventions in osteoarthritis, intra-articular injection with a corticosteroid is mentioned as an adjunct to conventional drug treatment in knee osteoarthritis

A recent systematic review ${ }^{17}$ summarised the findings of four randomised controlled trials investigating the effects of intra-articular corticosteroid injections in osteoarthritis. All

Table 2 Median changes in clinical variables within the steroid and placebo treated groups at each assessment point

\begin{tabular}{|c|c|c|c|c|}
\hline \multicolumn{2}{|l|}{ Clinical feature } & \multirow{2}{*}{$\begin{array}{l}4 \text { weeks } \\
18.5 \text { (3.5 to } 20.1) \\
p=0.34\end{array}$} & \multirow{2}{*}{$\begin{array}{l}12 \text { weeks } \\
23.3(6.0 \text { to } 29.3) \\
p=0.51\end{array}$} & \multirow{2}{*}{$\begin{array}{l}24 \text { weeks } \\
14.0(-12.5 \text { to } 16.9) \\
p=0.32\end{array}$} \\
\hline VAS & (PL) & & & \\
\hline & (ST) & $\begin{array}{l}10.5(-8.0 \text { to } 12.6) \\
p=0.15\end{array}$ & $\begin{array}{l}3.5(-8.5 \text { to } 4.9) \\
p=0.31\end{array}$ & $\begin{array}{l}0.0(-12.5 \text { to } 2.3) \\
p=0.52\end{array}$ \\
\hline Joint tenderness & (PL) & $\begin{array}{l}1.0(0.0 \text { to } 1.3) \\
p=0.53\end{array}$ & $\begin{array}{l}2.0(-1.5 \text { to } 3.1) \\
p=0.24\end{array}$ & $\begin{array}{l}2.5(-1.5 \text { to } 3.5) \\
p=0.25\end{array}$ \\
\hline & (ST) & $\begin{array}{l}0.0(-1.0 \text { to } 0.9) \\
p=0.32\end{array}$ & $\begin{array}{l}0.5(-1.0 \text { to } 1.0) \\
p=0.41\end{array}$ & $\begin{array}{l}0.5(-1.5 \text { to } 1.0) \\
p=0.54\end{array}$ \\
\hline $\begin{array}{l}\text { Patient's global } \\
\text { assessment }\end{array}$ & (PL) & $\begin{array}{l}0.5(0.0 \text { to } 1.2) \\
p=0.02\end{array}$ & $\begin{array}{l}1.0(0.5 \text { to } 1.5) \\
p=0.01\end{array}$ & $\begin{array}{l}1.0(0.5 \text { to } 1.5) \\
p=0.01\end{array}$ \\
\hline & (ST) & $\begin{array}{l}0.5(0.0 \text { to } 1.0) \\
p=0.02\end{array}$ & $\begin{array}{l}0.5(0.0 \text { to } 1.0) \\
p=0.04\end{array}$ & $\begin{array}{l}0.0(0.0 \text { to } 0.5) \\
p=0.19\end{array}$ \\
\hline $\begin{array}{l}\text { Physician's global } \\
\text { assessment }\end{array}$ & (PL) & $\begin{array}{l}1.0(0.5 \text { to }+\infty) \\
p=0.01\end{array}$ & $\begin{array}{l}1.5(0.0 \text { to }+\infty) \\
p=0.03\end{array}$ & $\begin{array}{l}1.0(0.5 \text { to }+\infty) \\
p=0.01\end{array}$ \\
\hline & (ST) & $\begin{array}{l}0.5(0.0 \text { to } 1.0) \\
p=0.02\end{array}$ & $\begin{array}{l}0.5(0.0 \text { to } 1.0) \\
p=0.03\end{array}$ & $\begin{array}{l}0.0(0.0 \text { to } 0.5) \\
p=0.18\end{array}$ \\
\hline Joint stiffness & (PL) & $\begin{array}{l}2.5(0.0 \text { to } 3.0) \\
p=0.17\end{array}$ & $\begin{array}{l}2.5(-10.0 \text { to } 3.8) \\
p=0.37\end{array}$ & $\begin{array}{l}5.0(-5.0 \text { to } 8.5) \\
p=0.21\end{array}$ \\
\hline & (ST) & $\begin{array}{l}0.0(-5.0 \text { to } 2.5) \\
p=0.35\end{array}$ & $\begin{array}{l}0.0(-7.5 \text { to } 1.3) \\
p=0.67\end{array}$ & $\begin{array}{l}0.0(-7.5 \text { to } 1.0) \\
p=0.58\end{array}$ \\
\hline
\end{tabular}

The values are median change (interquartile range) for each clinical feature at 4,12 , and 24 weeks compared with baseline measurements, along with the corresponding $p$ value for improvement in each variable. Data were analysed using the Mann-Whitney $U$ test. Significant values in bold.

PL, placebo group; ST, corticosteroid group; VAS, visual analogue score. 
trials investigated responses in knee osteoarthritis. Jones and Doherty ${ }^{9}$ noted a mild improvement in visual analogue score at three weeks with steroid injection (methylprednisolone, $40 \mathrm{mg}$ ) compared with placebo. In only two further trials were significant improvements in pain scores noted with steroid compared with placebo, ${ }^{8}{ }^{18}$ and the improvement was only noted at one week after the injection. In addition, the study by Friedman and Moore ${ }^{8}$ showed a marked placebo response similar to our own findings. In general the benefits of steroid injection appear to be short lived and at present it is difficult to identify any disease factors which may act as predictors of response.

The presence of clinical signs of inflammation at a joint has been mentioned as one possible indicator of response to steroid injection. It seems likely that the role of inflammation in osteoarthritis varies both with location and with time interval. ${ }^{19}$ In this study we did not find any significant change in the cardinal clinical features of joint inflammation-that is, joint stiffness or tenderness-with time.

The radiographic features of osteoarthritis have been shown to influence the clinical response to steroid injection. Plant $e t ~ a l^{20}$ noted that hip joints with an atrophic pattern on plain radiography responded less favourably than those with a hypertrophic or mixed pattern. Joint space narrowing did not, however, influence the analgesic response to steroid injection in hip osteoarthritis. Our cohort had radiographic evidence of moderately severe degenerative changes within the CMCJ on plain radiography and it is possible that this has been an important factor influencing response.

There are various caveats to this study. It was underpowered, which reflects the fact that patients with primary thumb base osteoarthritis are difficult to recruit for research projects. The trial was discontinued because of difficulties with recruitment. Patients in this category tend to have failed other forms of treatment available in the primary care environment and are usually at a moderately advanced stage of the disorder when they are referred to hospital specialists. Most patients in this study had moderate to severe osteoarthritis, which may reflect their poor response to treatment. Nevertheless, this is the first randomised controlled trial of this type of corticosteroid injection in hand osteoarthritis. The patients were a homogeneous group with regard to their baseline characteristics, and accuracy of delivery of the injected substance was attained by radiographic guidance.

\section{Conclusions}

In summary we found no benefit of steroid injection over placebo in moderate to severe osteoarthritis of the thumb base. Future research should concentrate on the clinical outcome following treatment delivered at the first presentation of pain within the primary care environment.

\section{Authors' affiliations}

G K Meenagh, J Patton, G D Wright, Department of Rheumatology, Musgrave Park Hospital, Belfast, UK

C Kynes, Department of Rheumatology, Royal Victoria Hospital, Belfast

\section{REFERENCES}

1 Armstrong AL, Hunter JB, Davis TRC. The prevalence of degenerative arthritis of the base of the thumb in postmenopausal women. $J$ Hand Surg $[\mathrm{Br}]$ 1994;19:340-1.

2 Mannoni A, Briganti MP, Di Bari M, Ferrucci L, Serni U, Masotti G, et al. Prevalence of symptomatic hand osteoarthritis in community-dwelling older persons: the ICARe Dicomano study. Osteoarthritis Cartilage 2000;8(suppl A):S1 1-13.

3 Pellegrini VD. The basal articulations of the thumb: pain, instability and osteoarthritis. In: Peimer CA, ed. Surgery of the hand and upper extremity, vol 1. New York: McGraw-Hill, 1996:1019-39.

4 Chaisson CE, Zhang Y, Sharma L, Felson DT. Higher grip strength increases the risk of incident radiographic osteoarthritis in proximal hand joints. Osteoarthritis Cartilage 2000;8(suppl A):S29-32.

5 Swiggart CR, Eaton RG, Glickel SZ, Johnson C. Splinting in treatment of arthritis of the first carpometacarpal joint. J Hand Surg [Am] 1999;24:86-91.

6 Mayer JH. Carpometacarpal osteoarthritis of the thumb [letter]. Lancet 1970;ii:270.

7 Stefanich RJ. Intraarticular corticosteroids in treatment of osteoarthritis. Orthop Rev 1986;15:65-71.

8 Friedman DM, Moore ME. The efficacy of intraarticular steroids in osteoarthritis: a double blind study. J Rheumatol 1980;7:850-6.

9 Jones A, Doherty M. Intra-articular corticosteroids are effective in osteoarthritis but there are no clinical predictors of response. Ann Rheum Dis 1996;55:829-32

10 Gaffney K, Ledingham J, Perry JD. Intra-articular triamcinolone hexacetonide in knee osteoarthritis: factors influencing the clinical response. Ann Rheum Dis 1995;54:379-81.

11 Altman RD, Alarcon G, Appelrouth D, Bloch D, Borenstein K, Brandt K, et al. The American College of Rheumatology criteria for the classification and reporting of osteoarthritis of the hand. Arthritis Rheum 1990;33:1601-10.

12 Jones A, Hopkinson N, Pattrick M, Berman P, Doherty M. Evaluation of a method for clinically assessing osteoarthritis of the knee. Ann Rheum Dis 1993;51:243-5.

13 Altman RD, Hochberg M, Murphy WA, Wolfe F, Lequesne M. Radiographic atlas for osteoarthritis of the hand, hip and knee. Osteoarthritis Cartilage 1995;3(suppl A):3-19.

14 Dieppe PA. Are intra-articular steroid injections useful for the treatment of the osteoarthritic joint? Br J Rheumatol 1991;30:199.

15 ACR subcommittee on osteoarthritis guidelines. Recommendations for the medical management of osteoarthritis of the hip and knee. Arthritis Rheum 2000;43:1905-15.

16 Pendleton A, Arden N, Dougados M, Doherty M, Bannwarth B, Biilsma JW et al. EULAR recommendations for the management of knee osteoarthritis. Ann Rheum Dis 2000;59:936-44

17 Kirwan JR, Rankin E. Intra-articular therapy in osteoarthritis. Ballieres Clin Rheumatol 1997; 11:769-94.

18 Dieppe PA, Sathapatayavongs B, Jones HE, Bacon PA, Ring EF. Intra-articular steroids in osteoarthritis. Rheumatol Rehabil 1980;19:212-17.

19 Creamer P. Intra-articular corticosteroid injections in osteoarthritis: do they work and if so, how? Ann Rheum Dis 1997;56:634-6

20 Plant MJ, Borg AA, Dziedzic K, Saklatvala J, Dawes PT. Radiographic patterns and response to corticosteroid hip injection. Ann Rheum Dis 1997;56:476-80 